\title{
Consideration on Surface Modification of Steel Dies to Reducing the Plastic Sticking in the Forming Process
}

\author{
Konstantin V. Shalnov ${ }^{1) *}$, Kensuke Uemura ${ }^{1)}$ and Yoshiro Ito $^{2)}$ \\ ${ }^{1)}$ Nagata Seiki Co. \\ 8-2 Kamisuwa, Tsubame, Niigata 959-0181, Japan \\ ${ }^{2)}$ Nagaoka University of Technology \\ 1603-1 Kamitomioka, Nagaoka, Niigata 940-2188, Japan \\ *Corresponding author: konstantin_shaln@itac-j.co.jp
}

( Manuscript received 8 March 2012; accepted 6 July 2012; published 30 September 2012 )

(Presented at Technical Session in the International Tribology Conference Hiroshima 2011 )

\begin{abstract}
Plastic parts such as syringe, phone cases, containers, etc. are formed in the mold under the molten temperature and with the high pressure. Plastic sticking to the mold surface during forming process is a serious practical problem for the manufacturing. The sticking limits mold lifetime, reduces production speed and degrades product surface quality. Mold material, surface condition, plastic chemical properties and molding parameters effect on the sticking. In this work, the effectiveness of surface treatments including mechanical polishing, plasma nitriding, hard DLC coating and $\mathrm{TiB}_{2}$ ion implantation were investigated in regards to reducing the plastic sticking on the steels - SKD61, HPM38 and PX5 surface. The surface finishing was characterized with surface roughness, hardness, friction coefficients and wettability. Adhesion strength of the steel - plastic interface for the plastic materials: polypropylene (PP), polystyrene (PS), polyethylene terephthalate (PET), poly-butylene terephthalate (PBT) were measured with the developed method, with the concept of real surface area. It was shown that, for the different plastics, the appropriate die material and die finishing must be chosen to provide the lowest plastic sticking.
\end{abstract}

Keywords: surface modification, surface real area, plastic sticking, adhesion strength, plasma nitriding, DLC, ion implantation

\section{Introduction}

The adhesion of the polymeric materials to the solid substrate is of considerable interest among the engineers and scientists, due to its importance for the various industrial applications. Much of the works in the area of the polymers adhesion are aiming to improve the adhesion to the various substrates. Such tasks are essential for the industrial areas like composite or adhesive materials development, polymeric coatings, paints, lubrication and etc. [1]. The opposite task is to reducing the adhesion of plastics, which is required, for example, in the various tribology applications or for the plastic forming industry and this task is less developed. The general difficulties in the investigation of plastic adhesion are connected with the variety of processes and factors which are involved in the adhesion process. These include interfacial van der Waals forces, chemical and/or hydrogen bonding, inter-diffusion, electrostatic interaction, mechanical interlocking and so on [2]. In the actual situations, one or mentioned combined mechanisms are essential. Also it needs to distinguish the general term "adhesion" and more practical term "adhesion strength". Adhesion, in general, is the phenomenon which is determined by physical-chemical properties of surface contact and can be characterized by the thermodynamic work of the adhesion, which is usually difficult or impossible to determine directly $[3,4]$. Practically, to characterize the adhesion interaction, the unit of adhesion strength is commonly used. It is determined with the force required to destroy the adhesion bonding on the effective contact area. Adhesion strength is determined not only by interfacial adhesive-substrate interactions, but also with such factors as loading condition, contact geometry, existence of the internal stresses, mechanical properties of the materials, temperature and so on. It needs to note also that the adhesion strength is the statistical unit and determined by the random distribution of the defects on the "adhesive-substrate" interface as well. It is summarized that the work of adhesion can correspond to the experimentally measured contact adhesion strength 
only in the model experiments at the equilibrium conditions with infinitely low loading speed, perfect interfacial contact, minimal internal stresses and so on. In the real experiments it is difficult to get such conditions and currently there is no universal method for the adhesion determination. For each specific case thus, the appropriate method must be selected according to the materials and the process features.

One of the industrial areas where the adhesion or sticking of plastics plays essential role is the plastic forming industry. There various plastic parts such as syringe, phone cases, containers, etc. are done in the mold under the molten temperature and the high pressure. For the molding process, the plastic sticking to the mold surface during forming is a serious practical problem. The sticking limits mold lifetime, reduces production speed and lowers product surface quality. Mold material, surface condition, variety of plastics chemical properties and molding parameters can affect the sticking process. Possibility to reduce and control plastic adhesion to the mold steel can provide significant advantage to the molding process.

Conventional methods to reduce the plastic sticking and facilitate releasing process are with the releasing solvents or solutions in aerosol, liquid or paste form. Typically they are sprayed or painted on the mold surface. Due to the involved high temperatures most of the solvents quickly degrade and require frequent cleaning and spraying, which affects product surface finish and overall productivity [5,6].

It can be said, that currently there is no systematic approach to the adhesion reducing problem, no satisfactory solid anti-sticking agent for the molding process, especially for the precise molds, and also there is no proper procedure or universal testing method for the evaluation of adhesion reducing. Generally mold surface must have sufficient wear resistance and friction properties, appropriate roughness, high chemical inertness as well as low adhesion with the processed plastic.

Attempts were done to apply solid thin film coatings as mold releasing anti-sticking agent. Review of applications of various coatings in the molding technology is presented in the [5]. For example, PTFE coating showed good plastics releasing, but its mechanical properties were not satisfactory. Carbides or nitrides coatings ( $\mathrm{TiC}, \mathrm{CrN}$, etc.) provide improvements in wear resistance and in some cases showed good releasing properties. Magnetron sputtered coatings for the mold steel protection is proposed in [7]. In the experiments, DLC (a-C:H) and $\mathrm{WS}_{2}$ coatings shows promising results for reducing the epoxy sticking and $\mathrm{MoS}_{2}$ coating shows even worse result than not coated steel. The results were to be referred with surface roughness and wettability data to some extent.

Besides the thin film coatings, such treatments as the ion implantation or plasma nitriding can be rather promising for the molds treatment than the conventional methods $[8,9]$. Nitriding can provide nitrogen saturated surface layer with increased hardness and with altered chemical properties [10] and ion implantation is the promising method for modification of surface layer properties by impregnation of foreign ions, without significant roughness or dimension changes $[11,12]$.

In the present work, the effectiveness of several surface treatment processes like mechanical polishing, plasma nitriding, hard DLC coating and $\mathrm{TiB}_{2}$ ion implantation were investigated with the developed method in terms of plastic adhesion strength for the typical mold steels - HPM38 ${ }^{\circledR}$ (Hitachi Metals), PX5 ${ }^{\circledR}$ (DAIDO STEEL) and SKD61(JIS). Adhesion strength to the steels for the different plastic materials: polypropylene (PP), polystyrene (PS), polyethylene terephthalate (PET), poly-butylene terephthalate (PBT) were directly measured by molding and releasing the plastic from the mold surface. Data are discussed in terms of roughness, wettability and treated surface properties.

\section{Experimental procedures}

\subsection{Characterization}

It is known that various factors affect the plastic adhesion to the mold surface. For example, surface morphology and its roughness, which influence on interlocking and plastic distribution along sides the mold surface. The chemical properties of the plastics affect chemical interaction/bonding with the mold materials. In the work, we characterized the treated surface in regards to the roughness and wettability. Effects of DLC coating, plasma nitriding and ion implantation of the mold surface were examined in regards to hardness and friction. For the plastic adhesion strength against the mold surface, the force required to release the molded plastic from the mold surface were measured. The amount of plastic that remains after the plastic releasing from the mold surface was taken in the account as well.

Surface morphology and roughness were measured with the Atomic Force Microscope (AFM) and with the Confocal Scanning Laser Microscope (LM). Average roughness $R a$ and average maximum height of the profile $R z$ were taken from the LM data. For the surface relief characterization, the roughness factor $f_{r}$ was applied. Roughness factor $f_{r}$ is defined as the ratio of real rough surface area to the projected flat area. For the ideal flat surface $f_{r}=1$ and for the rough surface $f_{r}>1$ in accordance with the surface relief. Usually $f_{r}$ is approximately estimated from the two-dimensional (2D) surface profiles [13]. Here, for the investigated surfaces, $f_{r}$ was directly calculated from the three-dimensional (3D) surface images obtained with the laser microscope. Firstly, the obtained images were treated with the microscope software to remove tilting and noise picks. Resulting 3D image is the matrix of heights representing the real surface relief with some allowance. As for an 
example, the part of such matrix with the dimensions 40 $\times 40$ points for HPM38 in the polished condition is shown in Fig. 1. The measured area for the test pieces was $149 \times 112 \mu \mathrm{m}$ and the matrix dimension for this area was $1024 \times 768$ points, thus, the distance between the neighboring points is about $0.15 \mu \mathrm{m}$. In the case, Z-axis scanning step was $0.01 \mu \mathrm{m}$. With these measuring parameters, most of the surface features, which can be created with the applied surface treatment processes, could be detected. For the calculation of the real surface area, each square unit area formed by four neighboring points was approximated with 4 triangles and summation of all the triangles along the matrix gives the real surface area. Calculated real area divided by the geometrical flat area $(149 \times 112 \mu \mathrm{m})$ gives $f_{r}$ value. For each test piece, $f_{r}$ was calculated for 5 randomly selected areas and the mean values were taken. Standard deviation for the obtained data was no more than $1-2 \%$.

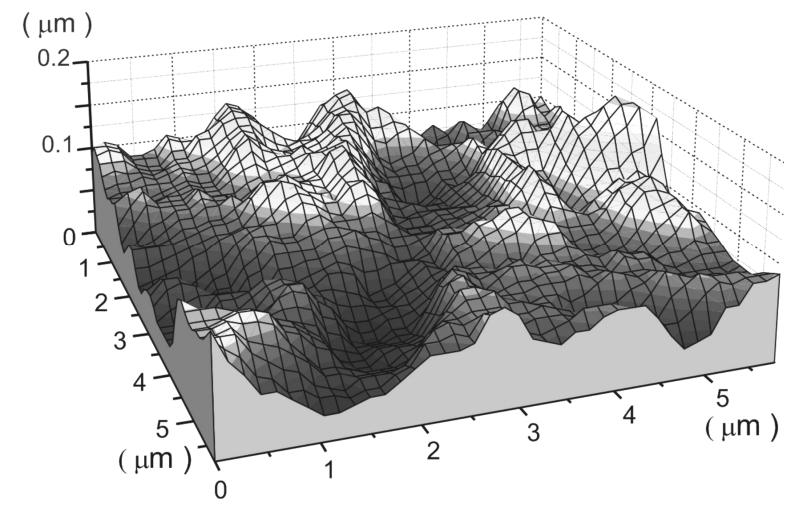

Fig. 1 Matrix of heights $(40 \times 40$ points $)$ obtained with the laser microscope for the surface of HPM38 in the polish\#1 condition.

Micro-hardness of the test pieces was measured with the Vickers Hardness Equipment with loads from 0.05 to $1 \mathrm{~N}$. Friction coefficients were measured with Surface Properties Tester HEIDON Tribogear 14DR using SUS ball indenter $(\phi 9 \mathrm{~mm})$ with load $1 \mathrm{~N}$, reciprocal sliding speed $-1200 \mathrm{~mm} / \mathrm{min}$ and stroke length $6 \mathrm{~mm}$. Tests were conducted in the ambient conditions with air humidity $\sim 40 \%$ without any lubrication. For each treatment process at least 10 hardness measurements and tribological tests were performed and mean results were taken.

Wettability of the treated surfaces was investigated with the contact angles method. Water contact angles were measured using standard optical goniometer with 2 $\mathrm{mm}$ water drop and $20 \mathrm{sec}$. holding time at the normal condition $\left(\sim 20^{\circ} \mathrm{C}, 40 \% \mathrm{RH}\right)$.

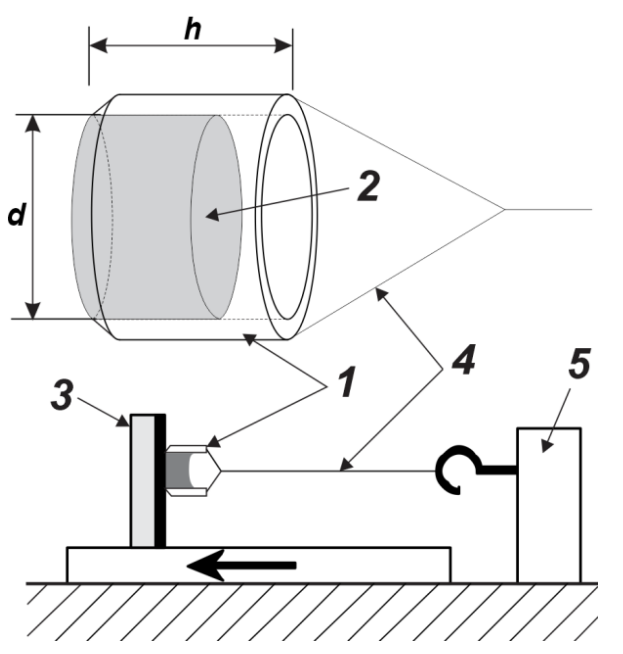

Fig. 2 Adhesion strength measurement schema. Stainless steel bushing (1) with $d=9 \mathrm{~mm}$ and $h=8 \mathrm{~mm}$ is filled with plastic (2) and molded on the steel test piece (3) that is fixed on the moving stand. Steel wire (4) connects bushing (1) with the lever of precision force meter (5).

Adhesion strength of the plastics was measured with the Surface Properties Tester HEIDON Tribogear 14DR. The experiment schema is shown in the Fig. 2. Firstly, the plastic in the steel bushing was set on the treated test piece and then it was molded with the temperature controlled heater. Plastic amount in the bushing was about $0.20-0.25 \mathrm{~g}$. On each test piece, 4 bushings with the plastic were set on. To minimize the bushing edge effect, the edges were sharpened from outside to form sharp declined edge. After the molding, the thickness of plastic in the bushing was $\sim 5 \mathrm{~mm}$, and, the area of the plastic contact with the test piece surface was $\sim 65 \mathrm{~mm}^{2}$. Heating temperatures were selected according to the typical plastic processing temperatures, for PET $-290^{\circ} \mathrm{C}$, PS $240^{\circ} \mathrm{C}, \mathrm{PP}-195^{\circ} \mathrm{C}$ and $\mathrm{PBT}-270^{\circ} \mathrm{C}$. Holding time was $40 \mathrm{~min}$. To minimize the effect of thermal stresses, the cooling was done together with the heater. Typically it took about $300 \mathrm{~min}$. Adhesion strengths were measured at the normal condition $\left(\sim 20^{\circ} \mathrm{C}, 40 \% \mathrm{RH}\right)$. Speed of the test piece removing was $10 \mathrm{~mm} / \mathrm{min}$. With the precise force meter, it allowed to measure the forces from $0.1-$ $20 \mathrm{~N}$. Maximum force of the plastic releasing was taken as adhesion strength value. Because of the statistical nature of the plastic releasing, at least 20 measurements were done and the mean value was adopted. Resulting adhesion strength were recalculated taking into account roughness factor $f_{r}$, i.e. influence of the real surface area.

For the reference purpose, the adhesion strength was measured with the solid Teflon test piece as well, which is known of its low adhesion to the plastics. 


\subsection{Test pieces treatments}

Test pieces of HPM $38^{\circledR}$, PX $^{\circledR}$ and SKD61(JIS) mold steels with the dimensions $50 \times 25 \times 15 \mathrm{~mm}$ were initially mechanically polished with rough $(3 \mu \mathrm{m})$ or fine grades $(0.5 \mu \mathrm{m})$ diamond pastes, further in the text we will refer the rough polishing process as "polish\#1" and fine polishing process as "polish\#2". Examples of AFM surface observations of $\mathrm{PX} 5^{\circledR}$ steel after the polish\#1 and polish\#2 are shown in the Figs. 3(a) and (b). Roughness, hardness, friction and wetting data for the treated test pieces are summarized in the Table 1 . Roughness data from the Table 1 show that polish\#2 gives smaller surface roughness comparing to polish\#1 for HPM38 and PX5 steels; and, accordingly, the calculated roughness factor of polish\#2 test pieces is smaller than that of polish\#1. It needs to note, however, that in general real surface area is not always proportional to the surface roughness, which was previously indicated by Donoso et al. [14]. Friction coefficients are bigger for polish\#2 than for polish\#1, and, this can be explained by the better contact of the indenter with the lower roughness surface. This phenomenon is in the accordance with literature data, for example [13]. For SKD61 steel, only polish\#2 process was applied.

It is known that surface roughness affects the wetting properties. Usually, for the hydrophilic surfaces, Wensel theory can be applied. It connects contact angle cosine to the roughness factor $f_{r}$ according to the formula:

$$
\cos \theta_{A}=f_{r} \cdot \cos \theta
$$

where $\theta$ is contact angle for the ideal flat surface and $\theta_{A}$ is apparent contact angle. It predicts that, in the case of hydrophilic surface $\left(0^{\circ}<\theta<90^{\circ}\right)$, rougher surface will give lower contact angle $[15,16]$. In the case of PX5, we have agreement with the Wenzel theory, but in the case of HPM38, the contact angle is bigger for the more rough polish\#1 comparing to the polish\#2 test pieces. This, probably, can be connected with the influence of higher $\mathrm{Cr}$ content in HPM38. In general, the influence of small roughness changes on the wetting properties of the fine polished surfaces was not well discussed in the literature. Previously, the effect of surface roughness, for various materials, was investigated in the numbers of works $[13,16,17]$, but usually the higher roughness levels or textured surfaces are in the consideration, and, there is some uncertainty in the wetting measurements for the small roughness levels.

Nitriding for HPM38 and PX5 were done with the volume discharge plasma under the non-sustain arc discharge with the heated cathode [18]. Test pieces after polish\#2 were treated for the nitriding. Temperature during the nitriding does not exceed $350^{\circ} \mathrm{C}(30 \mathrm{~min}$ heating with Ar ions bombardment), and, the nitriding time was $15 \mathrm{~min}$ (nitriding\#1) and $60 \mathrm{~min}$ (nirtiding\#2). The nitriding process generates Nitrogen rich surface layer with $\mathrm{Fe}$ and/or $\mathrm{Cr}$ nitrides. Depth of the surface layer modification is from $0.3 \mu \mathrm{m}$ to $2 \mu \mathrm{m}$ for the
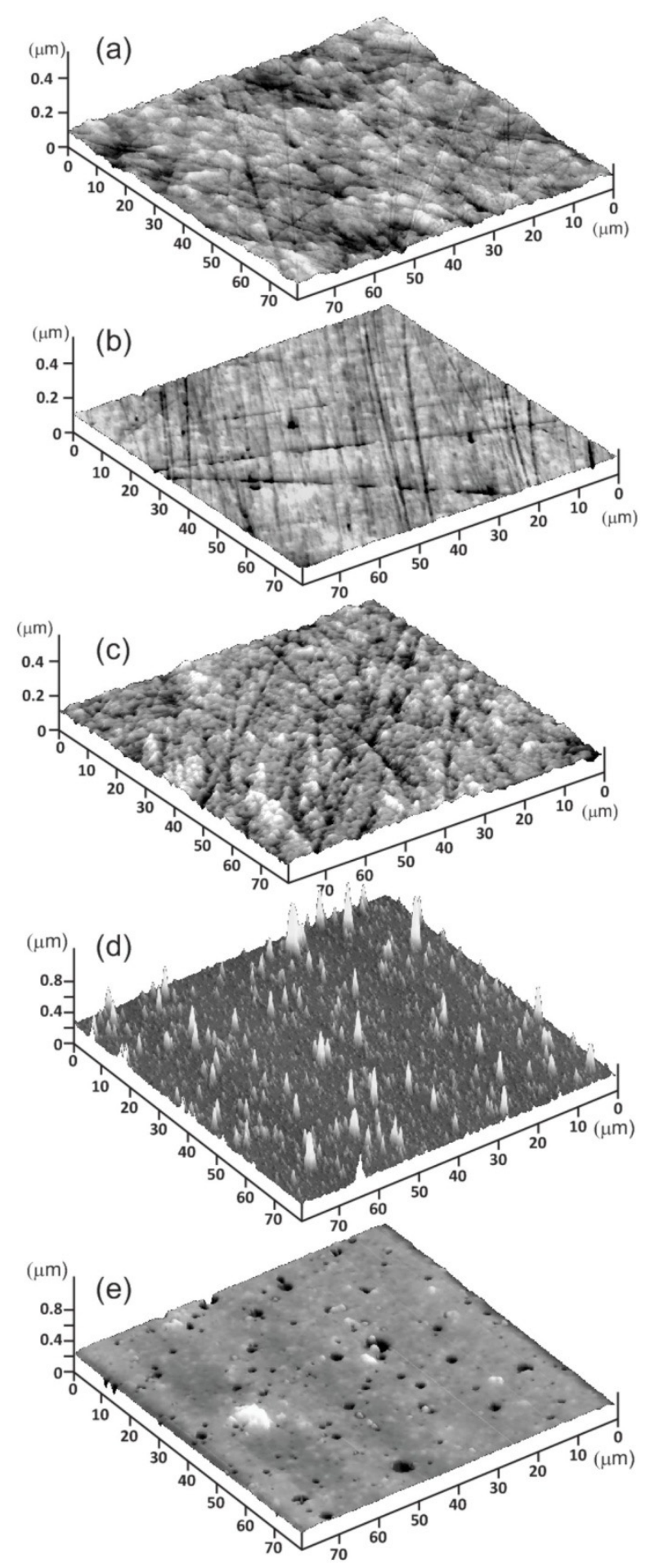

Fig. 3 Examples of surface morphologies of the investigated test pieces: (a) PX5 after polish\#1, (b) PX5 after polish\#2, (c) PX5 after nitriding\#2, (d) DLC coating as-deposited, (e) DLC coating after polish\#1. 
Table 1 Roughness, hardness, friction coefficient and contact angle for the steels test pieces.

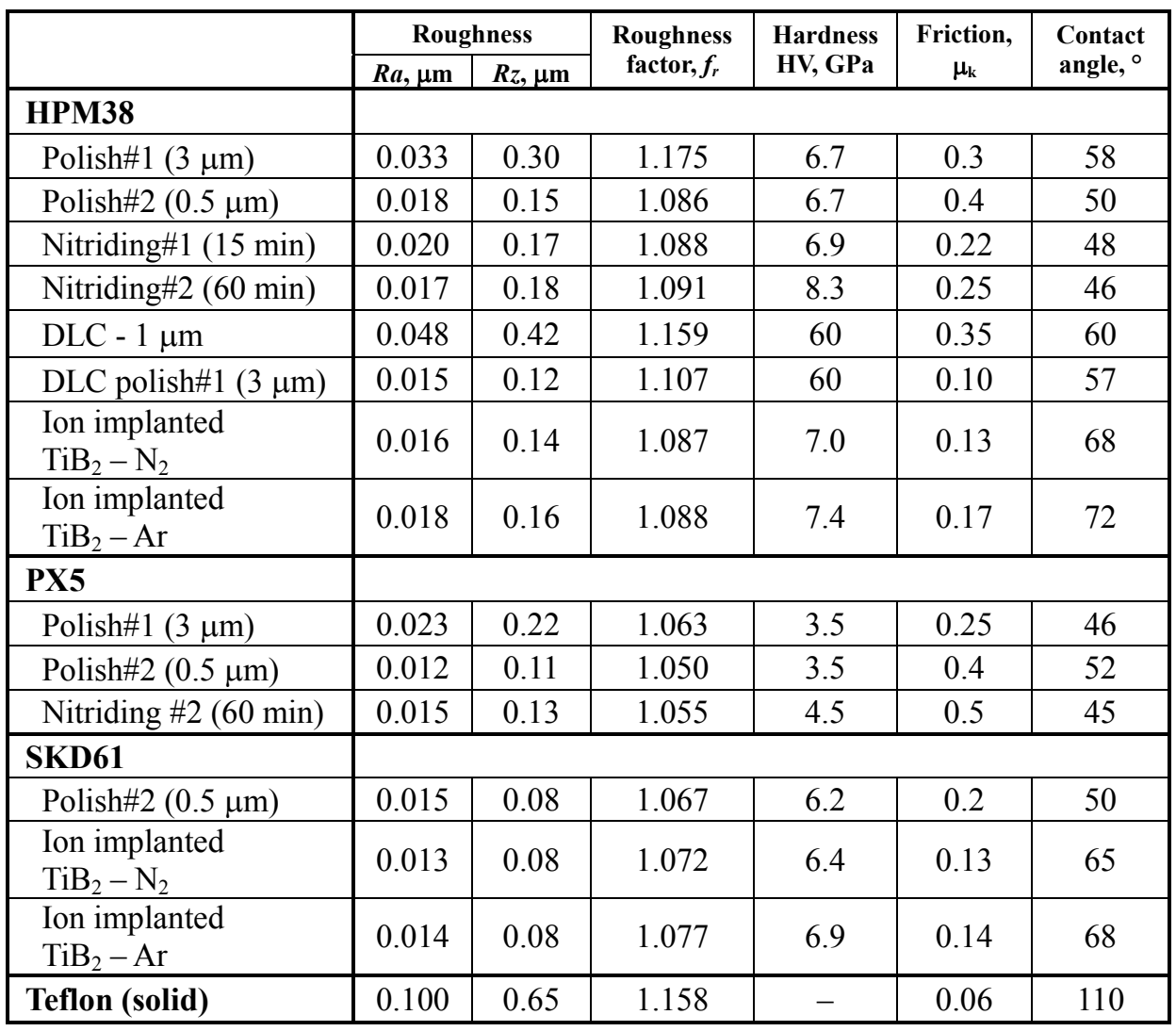

nitriding\#1 and \#2 respectively. Due to Argon and Nitrogen ions bombardment, the surface roughness can be increased continuing the nitriding. Parameters of the nitriding processes were selected to keep the surface roughness close to the initial. Nitriding\#1 gives the moderate effect on the surface hardness and after nitriding\#2, the hardness increased about $30 \%$ for both HPM38 and PX5 as shown in the Table 1. Roughness of test pieces was increased, as well as the calculated roughness factor $\boldsymbol{f}_{\boldsymbol{r}}$ accordingly. Example of the AFM surface image for PX5 test piece after the nitriding\#2 process is shown in the Fig. 3(c). Friction coefficients slightly decreased after the nitriding, which is connected with the influence of nitrides, as well as with the hardness increasing and the roughness effect. Wetting angles after the nitriding were also slightly decreased, which also can be explained with the influence of the chemically altered surface and/or with the influence of the slightly higher roughness according to Wenzel theory.

Hard DLC (tetrahedral amorphous DLC: $\mathrm{t}-\mathrm{aC}$ ) was coated on HPM38 with the method of graphite pulsed arc sputtering [19]. The coating thickness was about 1 $\mu \mathrm{m}$. The coating contains high $\mathrm{sp}^{3}$ (about $70 \%$ ) and is known of high hardness (up to $80 \mathrm{GPa}$ ), low friction coefficient and high chemical resistance. One of the phenomena of $\mathrm{t}-\mathrm{aC}$ films is the relatively high roughness in the as-deposited state, which is due to the large micro-particles emittance from the graphite cathode during the arc sputtering. Such particles lead to the formation of the micro-protrusions on the coating surface with the heights comparable with the coating thickness. Usually, for the tribology application, the polishing of $\mathrm{t}-\mathrm{aC}$ coatings is recommended. In the work, for the plastic adhesion measurements, we applied t-aC coatings in two conditions - (1) as-deposited and (2) after polish\#1. The surface morphologies are shown in the Figs. 3(d) and (e). From the Figs. 3(d), (e) and the data from Table 1, it can be observed that the polishing significantly modifies $\mathrm{t}$-aC surface morphology. Protrusions are mostly removed after the polishing, but, at the same time, some micro-pits appeared on the coating surface. Also, after the polishing, friction coefficient becomes rather low. As for the wetting properties, it can be observed also that there is no backing with the Wensel theory as the higher surface roughness gives higher water wetting angle. Such behavior can be connected as with the specific DLC morphology, as with the difference in $\mathrm{sp}^{2} / \mathrm{sp}^{3}$ content for as-deposited and polished states.

$\mathrm{TiB}_{2}$ ion implantations of HPM38 and SKD61 after polish\#2 were performed with the ion implanter on the 
base of the ion gun with $\mathrm{TiB}_{2}$ target, which are sputtered with low pressure discharge plasma of Argon or Nitrogen as working gas. Implantation of $\mathrm{TiB}_{2}$ was selected because $\mathrm{TiB}_{2}$ is rather promising material for the tribology applications, having high hardness, high wear resistance, exceptional chemical stability and oxidation resistance. However previous attempts to commercialize $\mathrm{TiB}_{2}$ coatings had not much success due to the high internal stresses and brittleness, which leads to peelings and tool failure [20,21]. Creating of thin $\mathrm{TiB}_{2}$ rich layer in the steel surface layer without boundaries with the substrate looks rather promising. The implantation energy in the process was $20 \mathrm{keV}$ and implantation fluence was $\sim 5 \times 10^{17}$ ions $/ \mathrm{cm}^{2}$. The implantation provides hardened, wear resistant and chemically different surface layer without noticeable roughness or dimension changes [12,22]. Depth of the surface layer modification for the performed ion implantation was about $10-20 \mathrm{~nm}$. Table 1 shows that the roughness generally did not change after the implantation, while the roughness factor was slightly increased, which can be explained by the partial surface sputtering with the high energy ions, and the effect is bigger for the implantation with the $\operatorname{Ar}$ than $\mathrm{N}_{2}$. The hardness was increased with Ar implantation, as it is heavier than Nitrogen and can create more defects in the substrate (dislocations hardening). For the friction coefficient decreasing, $\mathrm{TiB}_{2}$ implantation with the Nitrogen was more effective, due to the nitrides formation effect [22]. Wetting contact angles were significantly increased after the implantations, which is due to the formation of the novel phases in the surface layer (Ti-B/Ti-N, etc.).

\section{Results and discussion}

The mean adhesion strength data for the pairs of "steel-plastic" are summarized in the Table 2 and Table 3. Typical examples of the measured adhesion strength data are presented in the Fig. 4: (a) - for PS, (b) - for PET and (c) for PP. Fig. 4 exhibits the adhesion strength $(\mathrm{kPa})$ data, against the Test numbers $(\mathrm{N})$ from 1 to 20 for the surface treatment processes from 1) HPM38 polish\#2 to 6) PX5 nitriding\#2. The adhesion strength values showed, even in the trials of one specified surface treatment process, the wide deviation. For an example, in the case of PS with the PX5 after polish\#2, the measured adhesion strength values were from 330 to $25 \mathrm{kPa}$. Therefore, to clarify the image and to facilitate the perception, the adhesion strength data in the Fig.4 were sorted to plot the values descending for each set of plastic-steel, independently on the actual test number (N). These wide deviations mainly were due to the micro-defects in the contact area, which may appear during the molding process, and, with the influence of the bushing edges - steel surface boundary which could not be avoided completely.

Adhesion strength mean values $(\mathrm{kPa})$ with the
Table 2 Mean adhesion strength with PET, PS and PP for the surface treatment process of polished, nitriding and DLC coated.

\begin{tabular}{|l|c|c|c|}
\hline \multirow{2}{*}{} & \multicolumn{3}{|c|}{ Adhesion strength, kPa } \\
\cline { 2 - 4 } & PET & PS & PP \\
\hline HPM38 steel & \multicolumn{3}{|c|}{} \\
\hline Polish\#1 & 31.9 & 64.9 & 70.5 \\
\hline Polish\#2 & 23.7 & 59.7 & 65.9 \\
\hline Nitriding\#1 & 34.8 & 28.8 & 74.1 \\
\hline Nitriding\#2 & 38.8 & 13.9 & 78.2 \\
\hline DLC - 1 $\mu \mathrm{m}$ & 112.5 & $>300$ & 108 \\
\hline DLC polish\#1 & 54.8 & 114.6 & 86.9 \\
\hline PX5 steel & & & \\
\hline Polish\#1 & 56 & 140 & - \\
\hline Polish\#2 & 50.7 & 127.4 & - \\
\hline Nitriding\#2 & 34.2 & 110 & - \\
\hline Teflon (solid) & $<10$ & 12.3 & $<10$ \\
\hline
\end{tabular}

Table 3 PBT adhesion strength mean value for the polished and the ion implanted test pieces.

\begin{tabular}{|l|c|c|}
\hline \multirow{2}{*}{} & \multicolumn{2}{|c|}{$\begin{array}{c}\text { PBT plastic } \\
\text { adhesion strength, kPa }\end{array}$} \\
\cline { 2 - 3 } & $\begin{array}{c}\text { HPM38 } \\
\text { steel }\end{array}$ & $\begin{array}{c}\text { SKD61 } \\
\text { steel }\end{array}$ \\
\hline Polish\#2 & 30.8 & 23.7 \\
\hline Ion implanted $\mathrm{TiB}_{2}-\mathrm{Ar}$ & 8 & 5.7 \\
\hline Ion implanted $\mathrm{TiB}_{2}-\mathrm{N}_{2}$ & 14 & 20.1 \\
\hline
\end{tabular}

plastic of PET, PS and PP are shown in Table 2 in regards to HPM38 and PX5 with the surface treatment process of polish\#1, \#2, Nitriding\#1, \#2 and DLC coating (as-deposited and polish\#1). It is observed, that HPM38 exhibits almost half lower adhesion strength for PET, PS and PP comparing to PX5. This difference is thought to be derived from the higher $\mathrm{Cr}$ content in HPM38, which can contribute to the adhesion interaction reduction. It needs to note that neither roughness nor wetting angles contribute to reduce the adhesion strength. Meanwhile, in regards to the plastics, PET exhibits almost half adhesion strength than PP and PS. This phenomenon is evidently connected with the chemical properties difference of the plastics.

It is known that through the heating process, the plastics can be degraded and decomposed with the gases emission and/or formed into various chemical compounds, such as oxides, acids, salts and others [23-29]. These may interact with the substrate steel in one or another way and so influence on the resulting adhesion interaction. From the effect of the chemical transformations on the plastic-steel boundary through heating up process, the excess temperature of plastics 
must be taken into account. It needs to note that the three types of the investigated plastic materials, PP, PS and PET, have rather different decomposition behaviors, different temperatures of the decomposition initiation and variety of the resulting products.

In the cases of PP, thermal decomposition and
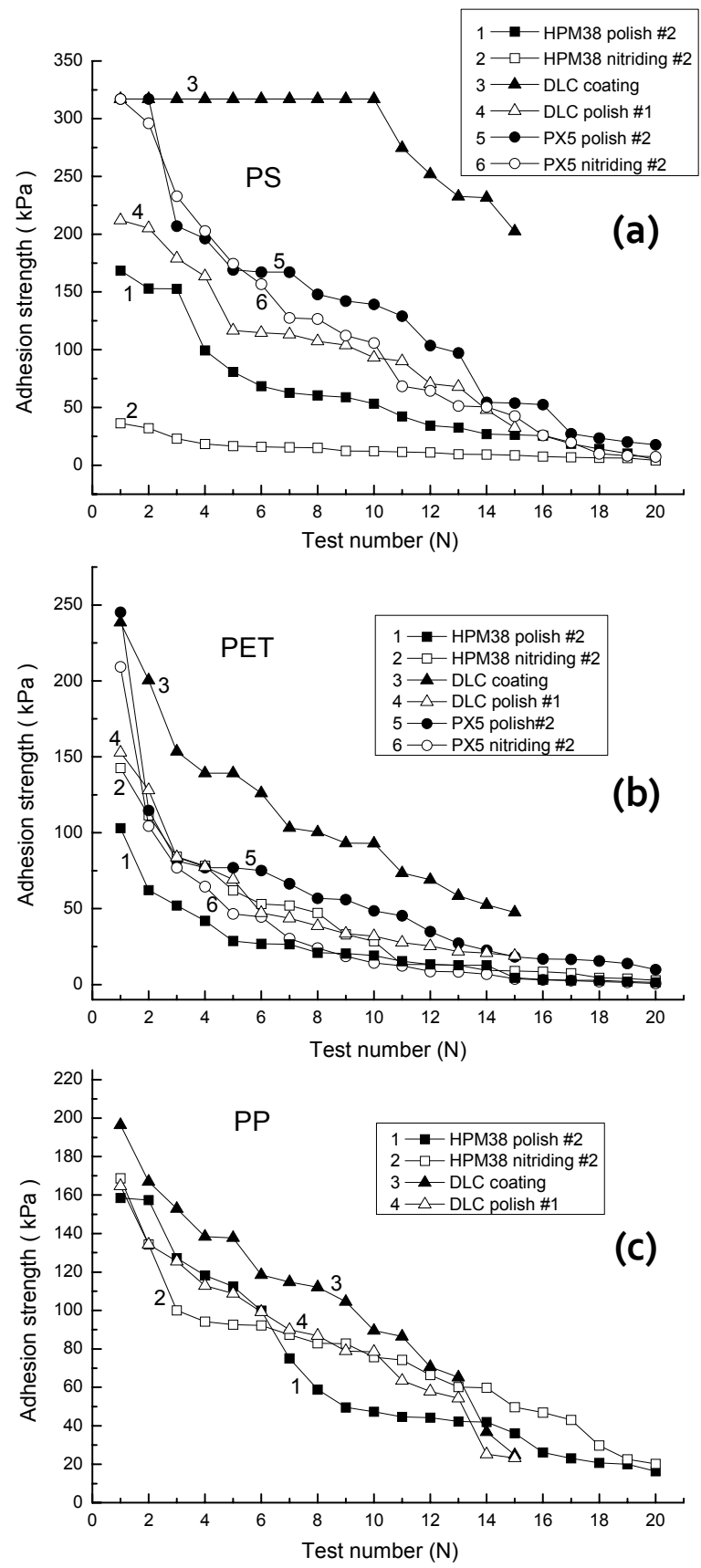

Fig. 4 Adhesion strengths of the (a) PS, (b) PET, (c) PP for HPM38 and PX5 with the polished, nitriding and DLC coated (as-deposited and polished) surface treatments. Due to the wide deviation of the adhesion strength values, the data were arranged with descending value with Test number from 1 to 20 . weight loss were detected at the temperatures higher than $230^{\circ} \mathrm{C}$ [23], but, at the same time, oxidation process starts at much lower temperatures $50-90^{\circ} \mathrm{C}$ [24]. It was reported that the product of the oxidative decomposition are mainly ketones. At the molding temperatures $\left(195^{\circ} \mathrm{C}\right)$, due to the oxidation, PP will be modified at the bushing boundary and degree of modification is limited by oxygen diffusion in the molten plastic. Thermal degradation of PP in the volume will not be effective, as the molding temperature is lower than that of the thermal decomposition initiation. In the experiments PP did not show any visible influence on the steel surface, however after the releasing, slight debris was observed on the steel surface at the areas of bushing edges.

For PS, decomposition is initiated at the temperatures higher than $300^{\circ} \mathrm{C}$ [23]. In [25], it was demonstrated also that, with oxygen presence, traces of the decomposition products could be observed starting from $200^{\circ} \mathrm{C}$; mainly they were styrene monomer, its oxides and hydrocarbons, however amount of the products was minimal. In our case, the molding temperature $\left(240^{\circ} \mathrm{C}\right)$ was lower than that of visible decomposition. No influence on the steel surface was observed after PS releasing, except minor debris at the bushing edges.

In the case of PET, decomposition process was confirmed already at $160^{\circ} \mathrm{C}$ [28], which is much lower than the typical molding temperatures $\left(290^{\circ} \mathrm{C}\right.$ in our case). It is said that PET decomposition process is rather complex and recently was investigated intensively $[26,28]$. Typically, as the main PET decomposition products, various oligomers, peroxides and carboxylic acids are mentioned. In the performed experiments, after PET releasing, no steel erosion or other surface alteration was observed. However, it was found that the resulting adhesion strength of PET was twice lower than that of PS or PP. It can be judged that expected decomposition products appearance could be responsible for the PET adhesion strength reducing, comparing to PP and PS cases, where much less influence of the thermal decomposition was anticipated.

As it was noted for PP, PS and PET, the debris amount on the steels surface after the plastic releasing was minimal. Mainly these residual materials were situated on the areas of the bushing edges. In the case, the total strength of plastic adhesion, measured in the experiments, can be considered as the sum of two parts: (1) plastic adhesion strength due to the interaction forces at the steel-plastic boundary; (2) part which acts on the areas of plastic remains. First part of total adhesion strength acts uniformly on the areas of the complete plastic releasing. This part depends on the plastic-steel interaction and expected to be nearly same for each selected combination of treated steel - plastic. The second part of total adhesion strength, depends on the areas of plastic debris. At the areas, the adhesion strength of the plastic to the steel is higher than the 
strength of the plastic itself. The deviation of adhesion strengths is thought to be mainly due to the influence of the plastic remains.

Several effects can be thoughts for the plastic remaining: (1) effect of bushing edges, which can give slight non-uniformity of plastic distribution on the edge areas, due to the not perfect bushing contact with the steel surface; (2) ambient oxygen influence and possible plastic degradation near the bushing edge area, the process can decrease plastic tensile strength near the boundary; (3) plastic micro-cracks, which can appear during the cooling process. These processes may give influence on the measured plastic adhesion in all the experiments, independently on the steel surface treatment, so they can be considered as the statistical error, to some extent, to the resulting adhesion strength data.

For the steel polishing effect, it could be observed that lower surface roughness provides slightly lower adhesion strength; such behavior was observed for all the tested pairs of rough and fine polished test pieces (polish\#1 and polish\#2). The adhesion strengths, depending on the Table 2, are shown in the Fig. 5 in regards to the roughness factor $f_{r}$ i.e. taking into account the real surface area. In the Fig. 5, it is observed that the specific adhesion strength for HPM38 with polish\#1 and polish\#2 for PS and for PP is almost same value. It can be said that, for the polished surfaces, correlation of the adhesion strength with the real surface area should be observed (excluding cases of interlocking). Substrates with the larger effective surface area will give higher adhesion strength values, in accordance with the roughness factor. However, for PX5, the difference of

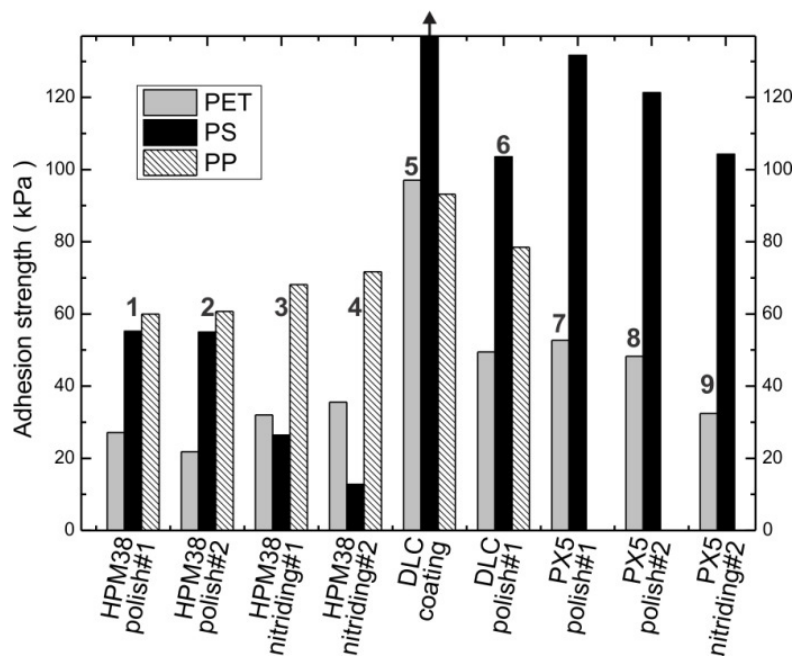

Fig. 5 Mean adhesion strength with surface roughness factor $\boldsymbol{f}_{\boldsymbol{r}}$ for the PS, PP and PET on HPM38: (1) polish\#1, (2) polish\#2, (3) nitriding\#1, (4) nitriding\#2; on the DLC coating: (5) as-deposited, (6) polish\#1; and on PX5: (7) polish\#1, (8) polish\#2 and (9) nitriding\#2 conditions. the specific adhesion strengths was observed for the different polished processes (Fig. 5). This can be affected by the contact defects at the bushings edges and with not sufficient statistical data.

In regards to the plasma nitriding process contribution, for the adhesion strength reducing, data is summarized in the Table 2. In the Fig. 4(a) it can be seen that the nitriding process significantly influences on PS adhesion strength. It is remarkable that for HPM38, the adhesion strength reducing is $\sim 80 \%$, and for PX5, it is $\sim 20 \%$ comparing with the polished state. The effect is predicted effective in proportion to the nitriding time duration.

Meanwhile, in the case of PET and PP, the adhesion strengths come bigger with the nitriding processes for HPM38, and, the nitriding duration effect is visible. For PX5, the adhesion strength of PET was slightly decreased to the level of PET adhesion strength for HPM38. These results exhibited that the nitrides compounds, which were formed in the surface layer, essentially influenced on the adhesion interaction between the plastic and the steel surface. The nitrides amount in the surface layer, which depends directly on the nitriding duration, influenced also on the degree of the adhesion interaction modification. The effect is connected with the chemical interaction of the plastics with the nitrided steel surface, and is not connected with the steel roughness or wettability, which were only slightly modified by the nitriding process.

Hard DLC coating influences for the adhesion strength are shown in the Table 2, Figs. 4 and 5. It is observed that the adhesion strength with the hard DLC coating was raised. This phenomenon cannot be explained only with DLC high roughness and with specific DLC surface morphology (Fig. 3(d)). After the DLC polishing, the adhesion strengths were decreased, but it still remains considerably high. It is thought that the carbon bonds existing on the DLC film surface may interact with the plastic chemical bonds to create rather strong adhesion interaction. It can be concluded that, in general, hard DLC coating is not recommended for the PS, PP or PET application except in the application only for PX5 wear protection.

$\mathrm{TiB}_{2}$ ion implantation with Nitrogen or Argon gases was applied to SKD61 and HPM38. The adhesion strengths after the implantation were measured for the PBT plastic. PBT is well known as the difficult material for the processing. PBT decomposes through the heating with the severe gas emission, acids and/or salts formation [29]. In general, PBT decomposition mechanism is similar to that of PET, however it was demonstrated that PET is much more stable comparing to PBT [28]. Also, same as in the case of PET, PBT decomposition initiation temperature is much lower, than typical processing temperatures.

For PBT molding experiments, significant plastic sticking and steel substrate erosion was observed, while for PET there was no such phenomenon. Fig. 6 (left 
(a) HPM38

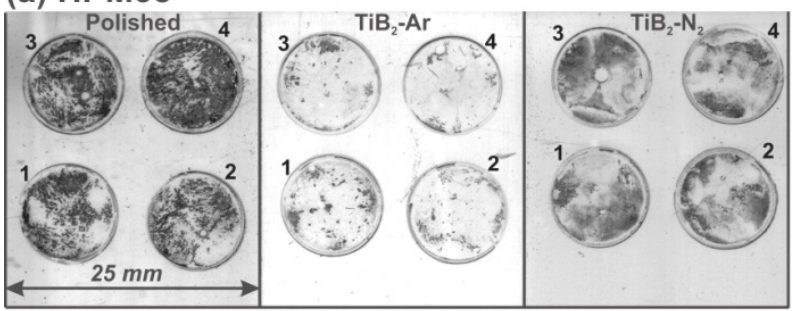

(b) SKD61

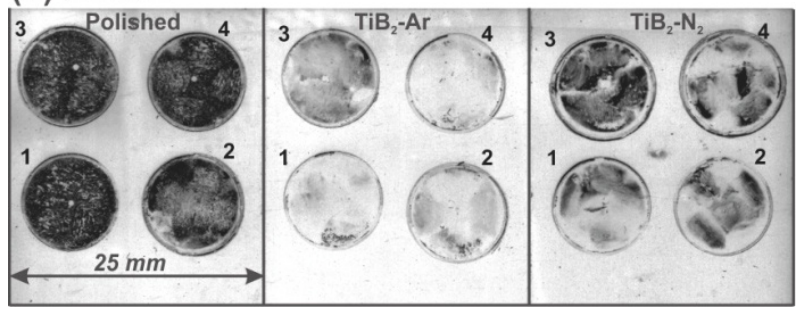

Fig. 6 Traces of the adhered PBT on the surface of the (a) HPM38 and (b) SKD61 test pieces after the plastic releasing. Left: polished surface, center: after $\mathrm{TiB}_{2}$ - $\mathrm{Ar}$ implantation, right: after $\mathrm{TiB}_{2}-\mathrm{N}_{2}$ implantation.

side) shows the remains of PBT after the adhesion strength measurement, typically for (a) HPM38 and (b) SKD61. It is observed that significant amount of the plastic was stuck in the polished condition for both HPM38 and SKD61. The adhesion strengths is associated not only with the adhesion bonding between the steel and the plastic, but mainly with the strength of thin PBT surface layer, which was modified (degraded) during the molding, due to the processing temperature. The tensile strength of the thin PBT layer is smaller than the strength of the steel - plastic adhesion contact.

Table 3 exhibits the mean measured adhesion strengths for HPM38 and SKD61 with the polished and with $\mathrm{TiB}_{2}$ ion implanted conditions. It is observed that the adhesion strengths for both HPM38 and SKD61 were decreased significantly with the implantation. In the case of $\mathrm{TiB}_{2}$ implantation with Argon, adhesion strength was reduced more than $80 \%$; and, in the case of the implantation with Nitrogen, the effect is considerably weaker. As it is shown in the Fig. 6, the amount of the plastic debris on the steel surface is in the accordance with the adhesion strength reducing. In the case of $\mathrm{TiB}_{2}-\mathrm{Ar}$ implantation, almost no adhered plastic could be observed on both SKD61 and HPM38 after the plastic releasing. And, in the case of $\mathrm{TiB}_{2}-\mathrm{N}_{2}$ implantation, the amount of adhered plastic is smaller than that of the polished steel condition; however, in the case, traces of the erosion is visible for both SKD61 and HPM38 after the plastic releasing. With the results, it can be concluded that Ti-B compounds, which were formed in the surface layer during the implantation, effectively reduced the adhesive interaction of PBT and its decomposition products with the steel substrate; though the nitrides, which were formed during the implantation with the Nitrogen gas, contributes negative. Therefore, for PBT processing, Nitrogen implantation or nitriding of steel substrate could not be recommended.

\section{Summary}

In the plastic forming process, the adhesion or sticking of the plastic remains to the die/mold surface is complicated phenomenon, including variety of the effects and parameters, which must be carefully considered during the investigations.

Experimental investigation of the adhesion process has been performed for the range of plastic materials and typical mold steels. Plastic adhesion strength to the mold steels was investigated with the concept of real surface area. Various surface properties, surface tribology and morphology were considered in regards to the influence on the plastic adhesion with additional surface modifications.

From the presented investigation the next conclusions could be made:

1) The steel composition significantly effected on the plastic adhesion process. It was shown that for the PS and PET plastics HPM38 steel provided two times lower adhesion strength comparing to the PX5 steel, which could be explained by higher $\mathrm{Cr}$ content in the HPM38 steel. However, for the PBT plastic HPM38 steel gave slightly higher adhesion strength, comparing to the lower Cr content SKD61 steel.

2) Plastics decomposition behavior due to the processing temperatures could be responsible for the adhesion strength variation for different plastic materials, additionally to the other chemical bonding mechanisms.

3) The lower substrate surface roughness led to the lower plastic adhesion. It can be concluded, that adhesion strength data correlated with the real surface area for the case of same material substrates with different roughness levels (excluding cases of interlocking).

4) Wetting properties variation for the evaluated substrates did not exhibit clear influence on the adhesion process; however, there is the trend of lower adhesion strength for the hydrophobic surfaces.

5) The properties of surface roughness or wetting angles showed some influence on the adhesion strength reduction, but the chemical interaction in the plastic and the steel interface showed more important factor.

6) Plasma nitriding reduced the adhesion strength of PS on HPM38 and PX5, but it was not effective for $\mathrm{PP}$ and PET adhesion.

7) Hard DLC coating did not provide any influence to reduce the plastic adhesion and, in general, DLC 
could not be recommended for PS, PP or PET molding applications.

8) $\mathrm{TiB}_{2}$ ion implantation with Argon, for SKD61 and HPM38, exhibited to reduce PBT plastic adhesion strength for about four times lower; also the amount of remains and sticking to the die surface were significantly reduced.

9) For reducing the sticking phenomenon, the optimized selection in between the plastic composition, die material and surface treatment should be considered depending on the stated combinations.

\section{References}

[1] Wu, S., "Polymer Interface and Adhesion," Marcel Dekker Inc, New York, 1982, 630.

[2] Garbassi, F., Morra, M. and Occhiello, E., "Polymer Surfaces: from Physics to Technology," John Wiley \& Sons, New York, 1998, 510.

[3] Kuskin, A. N., Sergeeva, L. M. and Lipatov, Y. S., "Determination of Quasiequilibrium Work of Adhesion of Elastic Coatings," Journal of Adhesion, 6, 3, 1974, 275-280.

[4] Hüttinger, K. J., Höhmann-Wien, S. and Krekel, G., "A Method for the Determination of the Acid-Base Interactions and the Work of Adhesion at a Solid-Liquid Interface," Journal of Adhesion Science and Technology, 6, 3, 1992, 317-331.

[5] Packham, D., "Mould Sticking, Fouling and Cleaning," Rapra Review Reports, 6, Rapra Tech. Ltd, 2002, 126.

[6] Hepburn, D., Kemp, I., Shields, A. and Cooper, J., "Effect of Mould Release Agent on Epoxy Resin Surface Degradation," Science, Measurement and Technology, IEE Proceedings, 146, 1999, 277-284.

[7] Zhang, S., Zeng, X., Tang, Z. and Tan, M., "Exploring the Antisticking Properties of Solid Lubricant Thin Films in Transfer Molding," International Journal of Modern Physics B, 16, 6/7, 2002, 1080-1085.

[8] Bienk, E. and Mikkelsen, N., "Application of Advanced Surface Treatment Technologies in the Modern Plastics Moulding Industry," Wear, 207, 1997, 6-9.

[9] Rodrliguez, R., Mikkelsen, N. and Tate, T., "SPRINT RA 372 Increasing European Industrial Awareness of Ion Implantation as an Effective Surface Treatment," Surface and Coatings Technology, 84, 1996, 584-589.

[10] Unterweiser, P. M. and Gray, A., "Source Book on Nitriding," ASM, Metals Park, OH (USA), 1977, 320.

[11] Straede, C. A., "Application of Ion Implantation in Tooling Industry," Nuclear Instruments and Methods in Physics Research B, 113, 1996, 161-166.
[12] Brukhov, V. V., "Tools Durability Increasing by Means of Ions Implantation," Tomsk, NTL, 2003, 120 (in Russian).

[13] Kubiak, K., Wilson, M., Mathia, T. and Carval, P., "Wettability versus Roughness of Engineering Surfaces," Wear, 271, 3/4, 2011, 523-528.

[14] Donoso, M., Mèmdez-Vilas, M., G.-M. A. and, Bruque, J. M., "On the Relationship between Common Amplitude Surface Roughness Parameters and Surface Area Implications for the Study of Cell - Material Interactions," International Biodeterioration \& Biodegradation, 59, 2007, 245-251.

[15] Wenzel, R. N., "Resistance of Solid Surfaces to Wetting by Water," Industrial and Engineering Chemistry, 28, 8, 1936, 988-994.

[16] Quéré, D., "Rough Ideas on Wetting," Physica A, Statistical Mechanics and its Applications, 313, 1/2, 2002, 32-46.

[17] Bico, J., Tordeux, C. and Quéré, D., "Rough Wetting," Europhysics Letters, 55, 2, 2001, 214-220.

[18] Vintizenko, L. G., Grigoriev, S. V., Koval, N. N., Tolkachev, V. S., Lopatin, I. V. and Schanin, P. M., "Hollow-Cathode Low-Pressure Arc Discharges and Their Application in Plasma Generators and Charged-particle Sources," Russian Physics Journal, 44, 9, 2001, 927-936.

[19] Trakhtenberg, I., Vladimirov, A., Rubstein, A., Kuzmina, E., Uemura, K., Gontar, A. and Dub, S., "The Analysis of Microhardness Measurement Approach for Characterization of Hard Coatings," Diamond and Related Materials, 12, 10/11, 2003, 1788-1792.

[20] Venugopal, K., Tawade, R., Prashanth, P., Paul, S. and Chattopadhyay, A., "Turning of Titanium Alloy with $\mathrm{TiB}_{2}$-Coated Carbides under Cryogenic Cooling," Proceedings of the Institution of Mechanical Engineers, Part B Journal of Engineering Manufacture, 217, 12, 2003, 1697-1707.

[21] Wiedemann, R., Weihnacht, V. and Oettel, H., "Structure and Mechanical Properties of Amorphous Ti-B-N Coatings," Surface and Coatings Technology, 116-119, 1999, 302-309.

[22] Shalnov, K., Kukhta, V., Uemura, K. and Ito, Y., "Applications of Combined Ion Implantation for Improved Tribological Performance," Surface and Coatings Technology, 206, 5, 2011, 849-853.

[23] Beyler, C. L. and Hirschler, M. M., "Thermal Decomposition of Polymers," SFPE Handbook of Fire Protection Engineering, 3rd edition, 2005, 110-131

[24] Gijsman, P., Hennekens, J. and Vincent, J., "The Mechanism of the Low-Temperature Oxidation of Polypropylene," Polymer Degradation and Stability, 42, 1993, 95-105. 
[25] Gurman, J. L., Baier, L. and Levin, B. C., "Polystyrenes: A Review of the Literature on the Products of Thermal Decomposition and Toxicity," Fire and Materials, 11, 1987, 109-130.

[26] Egorenkov, N., Kuzavkov, A. and Doctorova, V., "Contact Oxidation and Steel Adhesion of PET Coatings," High-Molecular Compounds, A24, Ya12, 1982, 2475-2481 (in Russian).

[27] Levchik, S. V. and Weil, E. D., "A Review on Thermal Decomposition and Combustion of Thermoplastic Polyesters," Polymers for Advanced Technologies, 15, 2004, 691-700.
[28] Botelhoa, G., Queiros, A., Liberal, S. and Gijsman, P., "Studies on Thermal and Thermo-Oxidative Degradation of Poly(Ethylene Terephthalate) and Poly(Butylene Terephthalate)," Polymer Degradation and Stability, 74, 2001, 39-48.

[29] Samperi, F., Puglisi, C., Alicata, R. and Montaudo, G., "Thermal Degradation of Poly(Butylene Terephthalate) at the Processing Temperature," Polymer Degradation and Stability, 83, 2004, 11-17. 